Palimpsesto Vol. 10, № 17 (enero-junio, 2020): 221-232

Universidad de Santiago de Chile, ISSN 0718-5898

Verónica Sentis Herrmann

Universidad de Playa Ancha

vsentis@upla.cl

\title{
Escenificando la tragedia del exilio: L'Attente/La espera, de Miguel Retamal, una dramaturgia chilena en Montreal*
}

\author{
Staging the Tragedy of Exile: L'Attente/La espera, by Miguel \\ Retamal, a Chilean Dramaturgy in Montreal
}

\begin{abstract}
Resumen
El presente artículo analiza la obra teatral L'Attente, de Miguel Retamal, planteando que para su correcta comprensión es necesario interpretarla no como un drama realista, sino como una tragedia contemporánea, cuyo argumento aborda la experiencia del exilio.

Se proponen los postulados trágicos del Albin Lesky como marco teórico para el estudio de dos temáticas inherentes al exilio: la tensión entre lealtad y fidelidad planteada por Judith Shklar y la tensión producida por los conceptos de destiempo y desespacio propuestos por Vasquez-Bronfman.
\end{abstract}

Palabras claves: Exilio, Dramaturgia, Postulados Trágicos, Lealtad-Fidelidad, Destiempo-Desespacio.

\begin{abstract}
This article analyzes the play L'Attente by Miguel Retamal, stating that for the correct understanding of it is necessary to interpret it not as a realistic drama but as a contemporary tragedy, whose argument adresses the experience of exile.

The tragic postulates of Albin Lesky are proposed as a theoretical framework to study two inherent themes of exile: the tension between loyalty and fidelity posed by Judith Shklar and the tension produced by the "destiempo" and "desespacio" concepts proposed by Vasquez-Bronfman.
\end{abstract}

Keywords: Exile, Dramaturgy, Tragic Postulates, Loyalty-fidelity, "Destiempo"-"Desespacio".

\footnotetext{
* El presente artículo es resultado del proyecto "Pasantía en Montreal, Canadá, estudios sobre teoría del exilio y el exilio latinoamericano en Quebec, en un marco crítico multicultural, desde una perspectiva polisistémica, traductiva y fronteriza con maestros universitarios eminentes" FONDART Nacional 2017, Folio: 400768.
} 


\section{Introducción}

Cuando examinamos la literatura del exilio, en este caso una dramaturgia producida bajo esas condiciones, nos enfrentamos, como plantea Lorenzano (2002, p.326), a una tensión que obliga a reflexionar sobre el punto de vista del análisis. Podemos, por una parte, estudiarla desde la perspectiva de la historia social que la genera, vale decir desde la relación texto-contexto que otorga ciertas condiciones para la producción de un objeto estético. Esto permite, al decir de Villegas, historizar el discurso estableciendo un vínculo con el contexto político-social en el cual fue creado, impidiendo así "la deformación del significado original a través de la imposición del sistema de valores y códigos del lector crítico" (1997, p.13).

Lo señalado por Villegas es sin duda pertinente, dado que la dramaturgia presenta una dimensión particular al ser concebida desde un inicio no como un producto artístico (texto) terminado, sino como un eslabón que se resuelve y modifica en el acontecimiento teatral. La mayoría de las veces se crea con el fin de ser representada, tejiendo el texto dramático de origen, cuando lo hay, con el conjunto de otros textos que componen el texto espectacular. Como plantea Gallina, la dramaturgia

No es obra en sí misma hasta que no se pliega a la cadena de trabajo que la transforma. [...] Ese reenvío que esta práctica genera siempre hacia otra dirección, hacia otros elementos, es la prueba irrefutable de su ser social. [...] se inscribe, en palabras de Rancière (2014), "en un régimen de las artes, un vínculo específico entre modos de producción de obras y prácticas, formas de visibilidad de esas prácticas y modos de conceptualización entre unos y otros". (2016, p.13)

Sin embargo, un objeto estético es una representación de la realidad que se suele analizar como universo autónomo. Acotar la comprensión de una pieza exclusivamente a su marco productivo es un punto de vista válido desde una mirada sociológica, pero no responde necesariamente al ámbito investigativo pertinente a la obra de arte. Por lo general, las creaciones son estudiadas en sí mismas y no sólo en relación con su entorno o como reflejo mimético de éste, pues se consideran independientes de su propio creador.

En consecuencia, más allá de su contexto de producción o de la experiencia particular de vida del dramaturgo, en el presente artículo analizaremos la obra teatral L'Attente bajo la hipótesis ahora planteada: entenderla como una tragedia contemporánea sobre el exilio, a pesar de su aparente aspecto de drama realista ${ }^{1}$. Vale decir, asumiremos que en este caso lo trágico debe comprenderse como un estilo teatral que excede la pureza del género y el origen social de los personajes protagónicos. Un conflicto sin resolución posible, en el que se ha entrado por un fallo humano, cayendo desde una condición de superioridad a otra miserable, que se sufre a

\footnotetext{
${ }^{1}$ Nos referimos al concepto de drama planteado tempranamente por Diderot en De la poesía dramática (1758), como un género que se encuentra en el centro de dos extremos correspondientes a tragedia y comedia. Este aborda conflictos de la gente común en situaciones extraídas de la vida cotidiana, aprehensibles por la razón y no de héroes aristocráticos que por su condición de tales remiten a situaciones elevadas o a fuerzas extra humanas. Posteriormente, desde fines del siglo XIX y durante la primera mitad del siglo XX, bajo la influencia de las ideas de Diderot, se añadió al concepto de drama el calificativo de realista, como una manera de especificar un tipo de teatro que no consiste solo en "narrar la acción, [...] sino en representar su medio y las condiciones subjetivas de su existencia” (Lescot, 2013, p. 196).
} 


\section{Verónica Sentis Herrmann}

conciencia y que quien lo especta debe sentir compasión, pues es testigo de una desgracia inmerecida (Lesky, 1966, pp.26-35)

Junto a la utilización de los postulados que Lesky señala como constitutivos del género: "Dignidad de la caída", "Posibilidad de relación con nuestro propio mundo", "Aceptarlo a conciencia, sufrirlo a sabiendas", "Oposición irremediable", "Culpa trágica” y "El acontecer trágico como portador de un sentido", proponemos que el carácter trágico se actualizaría en la obra a través de dos recursos temáticos inherentes al exilio:

1) La tensión entre lealtad y fidelidad como un conflicto irresoluble que sufren los personajes (Shklar, 1998).

2) La tensión del destiempo y el desespacio, como otra condición inherente al estado de exilio (Vasquez-Bronfman, 1991).

\section{Breves consideraciones sobre el autor y el contexto de edición de la obra}

L'Attente (La espera, en su versión en español) es una obra teatral escrita en francés por el exiliado chileno Miguel Retamal, quien abandonó el país en el año 1974, tras haber sido torturado. Luego de su arribo a Montreal vivió la experiencia de ser un refugiado político, a pesar de que Canadá no contó hasta 1978 con una ley de refugio, sino sólo de emigración. (Del Pozo, 2009, p.75). Cuando llegó a su nuevo país no tenía estudios dramáticos formales, pues sólo poseía una aproximación artística amateur, en calidad de animador teatral. Fue en Montreal donde pudo forjarse profesionalmente estudiando arte dramático en la Universidad de Québec en Montreal, ejemplificando con ello uno de los aspectos positivos que puede encarnar el exilio: el convertirse en "una escuela de aprendizaje" (Jensen, 2009, p.29).

La pieza fue estrenada en noviembre de 1994, por la compañía profesional Carré- Théâtre de Longueuil, en Montreal, mientras en Chile se vivía el primer período de la transición democrática. Su publicación en edición bilingüe, francés y castellano, fue realizada con fecha posterior a su estreno por la Editorial EDITEQ, Canadá, en 1997.

Teniendo en cuenta la nacionalidad del dramaturgo, el haber sido escrita en francés no constituye una elección neutra. Podemos inferir de ello que el deseo del autor era dirigirse al espectador quebequense y no solo a la comunidad de chilenos o latinoamericanos residentes, como sí hicieron otros teatristas exiliados durante el mismo período. Hay un interés de ir al encuentro de quienes no han vivido la experiencia, los posibles espectadores del país anfitrión, y persuadirlos de la tragedia de la migración mostrándoles un mundo al que no han estado expuestos. Si bien la pieza tiene breves parlamentos en castellano, la anécdota se desarrolla íntegramente en francés, en la Provincia de Quebec, y se alude sólo circunstancialmente a Santiago de Chile. Esta elección expone también su decisión respecto al medio artístico anfitrión. No es un exiliado que se parapeta en su diferencia como único espacio de resistencia posible, sino alguien que intenta integrarse.

El editarla en ambos idiomas puede ser también interpretado como un anhelo autoral subyacente: el que la pieza sea conocida en Chile, país en el que el artista es totalmente ignorado (tanto en su calidad de actor, como de autor y director), a pesar de ser su patria de origen. Hay en esta decisión un intento comprensible de reparación de lo dañado. Retamal se ha desarrollado exclusivamente en el circuito teatral montrealés. Es un desconocido para el medio escénico 


\section{Verónica Sentis Herrmann}

chileno, y aunque una acción como ésta puede interpretarse como un intento de reinsertar su producción a nivel nacional, lo cierto es que dada la ausencia de redes de difusión el texto nunca circuló ni fue estrenado en su tierra natal.

El argumento expone la historia de una familia chilena exiliada en Canadá. Observamos la vida de Manuel, Rosa y Matilda ${ }^{2}$, durante un lapso de casi veinte años. La pareja llega a Montreal en 1974 con un bebé en los brazos, para solicitar refugio político, condición que debe ser demostrada a través de enrevesados procedimientos legales y administrativos.

Si bien finalmente obtienen la residencia y se integran al mercado laboral, la experiencia es frustrante. Manuel realiza trabajos indignos, sin recuperar jamás su lugar social original. Rosa trabaja en una fábrica de costura junto a mujeres emigradas de todas partes del mundo, sin derecho a hablar durante su jornada laboral.

La culpa y la frustración provocan el alcoholismo del protagonista, lo que agrava la crisis del sistema familiar. Rosa decide abandonar a Manuel y volver a Chile con Matilda, pero regresa nuevamente a Montreal pues no se reconoce tampoco en su propio país.

La última escena, situada alrededor de 1994, nos muestra a Manuel dialogando con su hija, quien le comenta que no se considera chilena. Solo y envejecido, sentado en un banco de plaza en medio del invierno, Manuel se desnuda en la nieve mientras habla por fin con el fantasma de su hermana Tania, asesinada en dictadura, a quien él delató mientras lo torturaban.

\section{Temáticas y postulados trágicos}

1) La tensión entre lealtad y fidelidad como un conflicto irresoluble de los personajes.

Distintos autores (Shklar, 1998; Said, 2005; Faber, 2004) coinciden en que uno de los conflictos recurrentes que viven los exiliados está vinculado a la conciencia moral. Sobre todo si quienes toman la decisión de partir no han sufrido una persecución directa o permanente en su país de origen. Aquellos que se destierran porque no soportan habitar un lugar que ha cambiado radicalmente y en el que sienten, además, que están bajo amenaza vital.

Este es, claramente, el caso de Manuel. Su condición de exiliado por opción, que lo convierte más bien en un expatriado, queda reflejada en el cuestionamiento que le plantea la administración canadiense sobre si merece la calidad de refugiado político que solicita. El diálogo subraya lo sospechoso que puede volverse, a ojos extraños, una decisión radical que el individuo ha tomado porque subjetivamente la experimenta como la única posible:

Comisionado: Sr. Ramírez, según nuestras informaciones usted fue puesto en libertad de ahí en adelante. ¿Es cierto?

Manuel: Sí señor, cuando yo... [...]

Comisionado: ¿usted nos ha dicho también que no era un activista político en su país?

Manuel: Sí señor.

Comisionado: Consecuentemente, usted admitirá que sus declaraciones son muy ambiguas, y que no siendo un activista político, usted no tiene razones verdaderas para

\footnotetext{
${ }^{2}$ La versión en español presenta algunas diferencias con la escrita y estrenada en francés. La más importante de ellas es que el personaje de Matilda, la hija, se transforma en Matías. Para las citas del presente texto hemos optado por la propuesta original de personaje.
} 


\section{Verónica Sentis Herrmann}

reclamar la condición de refugiado político. [...] habría podido quedarse en Chile, puesto que ninguna acusación pesaba sobre usted.

Manuel: Si, posiblemente... [...] Pero yo vivía con el miedo de ser capturado de nuevo. (1997, pp.50-51)

Por otra parte, los estudios sociológicos muestran que quienes se quedan en un país bajo regímenes dictatoriales imaginan, muchas veces, que los exiliados viven una suerte de "exilio dorado" (Jensen, 2009, p.28). Esta imagen suele estar motivada por el éxito personal o laboral del emigrado en su nuevo destino o, simplemente, porque habita un lugar considerado más desarrollado que su tierra natal. El que dejó la patria es mirado como un traidor o como un individualista que ha puesto su bienestar personal por sobre los intereses colectivos.

En este contexto, como plantea Faber, el exiliado no sólo debe afrontar su tragedia personal de no pertenecer a ciencia cierta a ninguna parte, sino que se ve "ante el extraño deber de observar una constancia ética, ideológica, cultural e incluso lingüística que, en circunstancias normales, nunca se exigiría a nadie" (2004, p.36). La partida genera facciones entre personas que antes de la fractura eran aliados de un mismo bando. Esta disputa puede ser interpretada, sin duda, como otro triunfo de las dictaduras, las que logran fisurar consensos previos y trasladar el frente de lucha desde posiciones ideológicamente contrarias a conflictos internos dentro de un mismo grupo.

La obra presenta un protagonista obsesionado con la muerte de su hermana durante tortura. Vive asolado por sueños traumáticos, plagados de imágenes de la represión dictatorial. Manuel ve constantemente al fantasma de Tania intentando hablarle la que, se insinúa, fue delatada por él mismo. El sentimiento de culpa, la nostalgia y las frustraciones provocan su alcoholismo y con ello el hartazgo de Rosa, su mujer, con quien ya no logra entenderse ni prestarse mutuo apoyo

Rosa: Manuel, hace cuatro años que te despiertas cada noche gritando o llorando. Ya no puedo más. Tienes que hacer algo.

Manuel: Es raro, en mi sueño el soldado que me apuntaba tenía la misma cara del gerente del banco de aquí... y entre la gente que nos miraba estaba mi hermana Tania.

Rosa: Y claro, pues ella no estaba en el país de los sueños cuando fueron a buscarla.

Manuel: ¿Qué quieres decir?

Rosa: Que ella está muerta, que nosotros estamos vivos. Que estamos muertos en vida. Manuel: ¿Es un reproche? (va a buscar otra cerveza).

Rosa: No, pero yo me pregunto quién tiene más suerte, aquel que muere por sus ideales o aquél que está vivo, que respira, come y bebe pero que no es capaz de dormir por el peso de su conciencia. $(1997$, p.54)

El postulado de Lesky conocido como "la culpa trágica" propone que la caída se ha producido por un error que la genera. Un fallo, no una deficiencia moral. No se provoca por un rasgo perverso del personaje, sino por una falta que comete en su condición de humano, entendido éste como un ser que no posee la perfección de los dioses. En esa línea interpretativa, el texto muestra cómo Manuel no pudo resistir los tormentos y entregó a su propia hermana. Sin embargo, como lectores no podemos sino sentir compasión por él. Se lo exculpa, pues a pesar de 


\section{Verónica Sentis Herrmann}

haber delatado, la suya es sin duda una desgracia inmerecida, pues nadie logra salir vencedor de la tortura.

Por otra parte, el cuestionamiento de sus pares respecto a su coherencia ideológica, explícito o no, pone al exiliado en una disyuntiva moral a la cual se siente compelido a responder con una suerte de lealtad mayor, sin fisuras, que el propio transcurso del tiempo se encarga de desguazar.

Aparece así la tensión entre dos de los aspectos que Shklar plantea en su análisis del exilio: la lealtad versus la fidelidad ${ }^{3}$.

La autora define lealtad como el apego a un grupo social, de carácter afectivo y emocional, lo que la convierte más en un mandato moral que en una elección libre, consciente y mudable: "Political loyalty is evoked by nations, ethnic groups, churches, parties, and by doctrines, causes, ideologies, or faiths that form and identify associations" (1998, p.42). ${ }^{4}$

En contraposición estaría la fidelidad, planteada como una decisión voluntaria que vincula a un individuo con otro (amistades, relaciones de pareja, etc.) y que, por lo mismo, es susceptible de ser rota.

Este conflicto moral, que se desarrolla dentro de la conciencia del propio exiliado, se observa asimismo en la decisión de Manuel de no acompañar a Rosa en su retorno a Chile. A pesar de que él también añora el habitar de su tierra de origen, su lengua, sus propios sabores y la vida que perdió, siente que no puede, por lealtad, volver a un país en el que la dictadura sigue vigente y en el cual asesinaron a su hermana. Cuando debe escoger entre su amor a Rosa, con quien ha establecido un lazo de fidelidad, y la causa que lo llevó a abandonar el país, opta por esta última, aunque la lealtad sea una abstracción que no resuelve ninguno de sus problemas de la vida cotidiana:

Rosa: Sí, hay una cosa que todavía puedes hacer y es la única.

Manuel: ¿Qué?

Rosa: Volver a Chile con nosotros. Allá quizás...

Manuel: ¿Volver a Chile? [...] Yo no estoy preparado. Espera todavía un tiempo, te prometo que...

Rosa: $[. .$.$] Partiremos el día sábado en la tarde, dentro de dos semanas.$

Manuel: ¿Y cuándo vuelven?

Rosa: Jamás. Adiós, Manuel. (1997, p.65)

Lo absurdo es que la lealtad que el exiliado prioriza por sobre cualquier deseo personal es puesta en cuestión por la propia naturaleza del exilio, que no se constituye como un estado monolítico ni homogéneo. Como todo proceso evoluciona a través del tiempo, llegando a generar preguntas tales como cuándo se pasa de ser un exiliado a un emigrante o hasta cuándo es válida la autodefinición de un individuo como exiliado político.

Manuel no logra encontrar una salida, actualizándose así la "Oposición irremediable" señalada por Lesky. La contradicción moral en la que se encuentra no le permite vislumbrar solución. Su situación es paradójica, pues elija lo que elija indefectiblemente le traerá más

${ }^{3}$ Shklar propone cuatro aspectos referidos a la conciencia moral del exiliado: fidelidad, lealtad, obligación y compromiso. Para el caso de este análisis haremos referencia solo a dos de ellos, por ser los más pertinentes.

4 "La lealtad la evocan las naciones, los grupos étnicos, las iglesias, los partidos políticos, además de las doctrinas, las causas, las ideologías, o las fes que forman e identifican a las asociaciones" (T. del A.) 


\section{Verónica Sentis Herrmann}

sufrimientos. Para ser supuestamente leal a la causa se condena a sí mismo a vivir en un país que no es el suyo, en el que no logra rehacer satisfactoriamente su vida. Pierde así definitivamente a su mujer y a su hija, quienes ya no están dispuestas a continuar apoyándolo.

Ninguna decisión le permite concretar sus propios deseos y el de Rosa: desexiliarse (Benedetti, 1985). Volver a un habitar natural, sin conciencia de otredad, regresando a su patria y a la estabilidad de la vida anterior. Cualquier movimiento lo aleja más del origen y profundiza su miseria, encarnando otro de los postulados entendidos como trágicos: "dignidad de la caída". Personajes que tienen una condición previa de felicidad o estabilidad, en este caso la vida que ambos tenían en Chile durante el gobierno de Salvador Allende, condición que pierden indefectiblemente hundiéndose en la desdicha.

Rosa: Manuel, has cambiado tanto [...] ¿Te acuerdas de Chile? [...] Tú te dormías con tu cabeza pegada a mi vientre susurrándome palabras de amor en mapuche. Yo me sentía la mujer más importante de la tierra. [...]

Manuel: ¿Tú piensas que tengo ganas de cantar cuando vuelvo del trabajo? ¿Después de limpiar cientos de tazas de wáter llenas de mierda o de vómitos de turistas que han tomado o comido demasiado? [...] No, lo único que tengo son ganas de tomar, para olvidar. $(1997$, p.56)

2) Destiempo y desespacio, otro conflicto irresoluble.

Como comenta Vasquez-Bronfman, una característica del exilio es la imposibilidad de recobrar el tiempo y el espacio perdido, incluso si se retorna al país de origen. La salida se constituye, entonces, en una fisura vital definitiva, que no se logra revertir a través de ningún acto reparatorio.

Cuando un exiliado vuelve a su tierra natal lo hace con la ilusión de recuperar, en esta acción, un modo de habitar perdido con el destierro. La reconquista de su lengua, lazos familiares, tradiciones y sabores, se le aparecen como el término de un penoso periodo de vida en el cual la naturalidad cotidiana, entendida como un devenir que se atraviesa sin cuestionamientos, sería nuevamente alcanzable.

l'exilé voudrait non seulement récupérer l'espace, mais revenir en arrière dans le temps pour retrouver son espace social intact, récupérer sa famille telle qu'elle était quand il l'a quittée, récupérer l'espace de son enfance, re-créer un monde qui n'est plus (1991, p.221 $)^{5}$

La experiencia demuestra que es una ilusión destinada al fracaso, pues el país al que se retorna ya no es el mismo que se recuerda, dado que "ningún regreso permite volver: todo regreso es como volver a partir, pero en sentido inverso, porque todo ha cambiado, empezando por el migrante mismo" (Trigo, 2003, p.59)

Esta condición de carácter trágico, que alude nuevamente a un conflicto que no tiene resolución, vale decir a una "oposición irremediable", es encarnado aquí por Rosa, mujer de

5 "El exiliado quisiera no solo recuperar el espacio, sino volver hacia atrás en el tiempo, para recuperar su espacio social intacto, recuperar su familia, tal y como era cuando la dejó, recuperar el espacio de su infancia, recrear un mundo que ya no existe". (T. del A.) 


\section{Verónica Sentis Herrmann}

Manuel. Ella abandonó Chile sin estar motivada por la lealtad, sino por la fidelidad a su esposo. Asume durante un tiempo las consecuencias de una opción ética ajena, hasta que sus propias necesidades como mujer y su proceso individual la llevan a emprender, acompañada de su hija, el camino de retorno. Como respuesta a sus expectativas, cuando llega a Chile comprueba que ha sido contagiada por la peste del exilio y condenada a vivir eternamente en una condición fronteriza: "Rosa: No te cuentes historias. Ya no tenemos patria. Ya no tenemos nada" (1997, p.55).

Haga lo que haga el destiempo y el desespacio se asentaron en su vida y el regreso, que pretendía quebrar "el estado de discontinuidad del ser" (Said, 2005, p.184), se muestra como lo que es: una utopía forjada en la distancia. En virtud de las circunstancias el personaje no tiene opción, pues "el [propio] destierro conduce a ese destiempo, a ese décalage o desfase de los ritmos históricos de desenvolvimiento que habrá significado para muchos el peor de los castigos. La expulsión del presente; y por lo tanto del futuro -lingüístico, cultural, político- del país de origen" (Guillén, 1998, p.83).

La pieza narra los variados intentos de Rosa por adaptarse al nuevo Chile, en los que fracasa cada vez. Si bien esta información expone su propia frustración, es Matilda, en calidad de tercero observante del conflicto, quien lo expresa indirectamente en sus diálogos en distintas escenas de los veinte años que constituyen el tiempo poético de la obra.

Manuel: ¿Has tenido noticias de tu madre?

Matilda: Sí, frecuentemente,

Manuel: ¿Y?

Matilda: Como de costumbre. Me cuenta que se siente demasiado sola allá. No ha sido capaz de acostumbrarse a Chile. Va a volver para acá. (1997, p.85)

Es interesante observar cómo a través del protagónico femenino, encarnación de los valores del hogar en su calidad de matriz, de nido original y refugio primigenio ${ }^{6}$, se resalta lo irremediable de la situación. El exilio como "un cronotopo de crisis, una forma de desterritorialización afectada negativa y patológicamente por la expulsión violenta de sus sujetos de unas coordenadas fijas de tiempo y espacio: una crisis de tiempo tanto como una crisis de espacio" (Balibrea, 2007, p.83) imposible de ser resuelta.

En ese mismo sentido, es Manuel el encargado de rematar la obra subrayando la imposibilidad de resolver dicho conflicto. Cuando finalmente toma la decisión de volver, pues ha terminado la dictadura y no teme ya a la represión, no tiene con quién hacerlo. Su mujer lo dejó definitivamente y ha experimentado ella misma su propia decepción al respecto. Matilda, la hija, se siente extraña en Chile y se considera quebequense. Los veinte años vividos en Montreal son irreversibles y han significado la destrucción de lo único que pudo rescatar de su país: el núcleo familiar. Aun cuando los motivos que generaron la partida se desvanecieron y es posible el retorno, Manuel ha cambiado de tal modo que ya no es un ciudadano de su nación de origen, sino un exiliado, incluso en su propia tierra. Alguien que mira los sucesos desde una óptica otra, en el que no cesa de ser un extraño. Los frustrados intentos de volver a Chile por parte de Rosa y hacia

${ }^{6}$ Así lo resalta acertadamente Jane Moss, al analizar varias piezas de Retamal como obras representativas del teatro emigrante en Quebec. La investigadora pone en valor la sensibilidad que muestra este dramaturgo para reflejar las dificultades particulares de las mujeres, dentro de los complejos procesos de adaptación migratorios, mostrando cómo se reconfiguran las familias (y sus roles tradicionales) bajo la experiencia crítica del exilio (2004). 


\section{Verónica Sentis Herrmann}

el final de la obra, de Manuel, los vuelven conscientes de lo irreparable de su situación. La extranjería se torna trágica, justamente, porque es soportada desde la lucidez. Ambos personajes deben "Aceptarlo a conciencia y sufrirlo a sabiendas", aunque no puedan resolverlo.

Finalmente la experiencia del exilio, encarnada mediante la sucesión de elementos infaustos de la obra, conduce al protagonista a su auto aniquilación. Manuel entra en un estado de locura que lo lleva a dejarse morir bajo la nieve, teniendo como único interlocutor al fantasma de su hermana, personificando el héroe trágico que "se ve enfrentado a una fuerza superior que lo obliga a sacrificar una parte de sí mismo, hasta llegar incluso a la muerte” (Burgos, 2007, p.54).

Manuel: (Está como mareado. Se levanta y sale lentamente sin mirar a su hija. [...]) El exilio es un animal cronófago, es una bestia inmunda que ha engullido mi tiempo... el tiempo pasa tan rápido.

Matilda: ¡Papá! ¡oye papá! ¡escúchame!

Manuel continúa caminando y hablando al mismo tiempo. La obscuridad invade la escena y se ve a Manuel que marcha en círculos [...]

Manuel: Si, un día, un día... Tania. [...] Ellos querían nombres. Yo no fui capaz de resistir. Qué le vamos a hacer, uno se cree siempre más grande de lo que es en realidad. [...] Fui tan cobarde. [...] Yo tenía tanto miedo de no verte nunca más. [...] ¡Escucha! ¿Oyes? El pueblo unido jamás será vencido, no era más que el ruido de las olas. Yo también creía, yo también creía... (1997, pp.88-89)

Esta situación que cierra la obra con la aniquilación total del héroe intentaría, según Lesky, proponernos una lógica última más allá de la frágil cotidianidad de nuestro mundo: "Su muerte es inevitable, pero en modo alguno carece de sentido. Todavía no está madura la época para el valor por el cual él lucha y cae, pero su sacrificio hace expedito el camino de un futuro mejor" (1966, p.42).

Se cumple así el postulado que considera "el acontecer trágico como portador de un sentido" si interpretamos el problema del exilio como una situación que deberíamos ser capaces de resolver como naciones, a través de una progresión dialéctica ascendente (tesis-antítesissíntesis), evolucionando como seres humanos hacia una condición socio-política y moral más elevada.

\section{Conclusiones}

Como primera conclusión, consideramos fundamental establecer una distinción entre dramaturgia del exilio y sobre el exilio, antes de comenzar un análisis. La primera correspondería a cualquier obra dramática producida por un autor en estado de exilio, más allá de la temática de la misma. La segunda, a textos cuya fábula, vale decir el tejido argumental, aborda la problemática del destierro dentro del universo narrado.

Es justamente en los casos de dramaturgia sobre el exilio, que los aspectos temáticos lealtad-fidelidad y destiempo-desespacio actualizan una pugna que los personajes protagonistas mantienen consigo mismos, con el país anfitrión y el país de origen, otorgando un marco concreto en el que evoluciona la acción. 


\section{Verónica Sentis Herrmann}

En L'Attente podemos observar cómo se produce una coincidencia entre los elementos constitutivos de la tragedia, planteados por Lesky, y los aspectos temáticos de la pieza descritos por Shklar y Vásquez-Bronfman. Dicha combinación logra amplificar el argumento, generando un desarrollo que supera la simple anécdota de los personajes y sus vidas cotidianas.

En este marco narrativo el exilio se evidencia como un estado trágico, al constituirse como un conflicto sin resolución posible. Lo anterior nos permite reflexionar sobre las vivencias de un ser humano que, tras el destierro, no puede nunca recuperar la condición que detentaba antes de la caída.

Sin lugar a dudas, cuando el extrañamiento se experimenta transforma para siempre a quienes lo sufren, dejándolos en una condición fronteriza en la que ya no son ciudadanos de la cultura de origen ni miembros de la cultura anfitriona. Han sido desprendidos por la fuerza de su crianza primordial, sin lograr asimilarse totalmente a su nueva tierra.

Al obtener el estatuto de tragedia, la obra se convierte en una reflexión sobre la condición humana en el mundo actual, a la que nadie puede permanecer impávido. Experimentamos, como plantea Williams en su reflexión acerca de la tragedia de la revolución, "la compasión y el terror en la percepción de un disturbio radical en el que la humanidad de algunos hombres es negada y, por lo tanto, se niega la misma idea de humanidad. Nace en el sufrimiento del hombre real así expuesto, y en todas las consecuencias de este dolor: degeneración, embrutecimiento, miedo, odio, envidia. Nace en la experiencia del mal, convertida en la más intolerable de las experiencias por su condición de inevitable, pero es el resultado de acciones y elecciones particulares" (2014, p.100).

En el caso analizado se cumple además una condición esencial del género trágico, reflexionar, a través de una historia individual, sobre conflictos universales que aquejan al hombre. En la obra, mediante el relato de la vida de Manuel, Rosa y Matilda, podemos empatizar con el conjunto de experiencias particulares que sufrieron los exiliados latinoamericanos desde fines de los años sesenta. Nos permite mirar el impacto del destierro desde entonces hasta nuestros días, evidenciando la imposibilidad de reparación y la continuidad del conflicto, más allá del retorno de las democracias de postdictadura.

Así, al teatralizar/escenificar la penalidad del exilio, se posibilita un marco multiperceptual del tema, pues el teatro propone un acontecimiento escénico que implica la reunión en cuerpo presente de espectadores y actores en una misma coordenada territorial. Vale decir "la experiencia conjunta de los cuerpos reales en un espacio real" (Fischer-Lichte, 2011, p.73) en el que mediante la vivencia grupal pensamos, emocionamos y analizamos en conjunto a través de la experiencia del convivio, que nos reenvía a una escala ancestral de la humanidad. (Dubatti, 2002)

Este acercamiento de carácter convivial excede lo intelectual, para convertirse en un acontecimiento integral donde no sólo nos enteramos racionalmente de los conflictos que padecen los exiliados, sino que percibimos sus sufrimientos a través de la conmiseración que produce atestiguar las aflicciones de otro. La pieza de Retamal propone así una dramaturgia que se emparenta con variadas producciones de finales del siglo XX que encarnan, como plantea De La Maza "los conflictos del hombre de fin de siglo [...] anunciando la tragedia del hombre común” (2007, p.63).

A través de la ficción y de la posibilidad de copresencia inherente a la autoría dramática, la obra se opone a la política de olvido propugnada por los primeros gobiernos democráticos chilenos. Promueve un teatro que dé cuenta no sólo de las vicisitudes sufridas dentro de los países latinoamericanos bajo las dictaduras militares, sino que integre la vivencia de quienes se 
fueron al ser compelidos a abandonar su tierra. Bosqueja una mirada del exilio que encarna las tensiones de esta condición, desplegando la complejidad ideológica que la envuelve. Se aleja de una visión maniquea que simplifica la experiencia, dividiendo entre consecuentes e inconsecuentes, y expone los diversos matices y contradicciones de una condición desde la cual no existe retorno. Al hacerlo, se actualiza y establece "La posibilidad de relación con nuestro propio mundo", sobre todo en un momento en el que las migraciones masivas son cada vez más frecuentes. En este contexto la ficción dramática nos conmueve y busca la catarsis, generando horror y conmiseración en los percipientes a través de un proceso de identificación, pues representa una situación que en cualquier momento podría ocurrirnos a nosotros mismos.

Como plantea Lehmann (y esta obra demuestra), la tragedia como género pervive, justamente, porque hemos descubierto que a pesar de la razón y de la prosperidad del hombre, hay contradicciones que no son posibles de ser superadas mediante el consenso. Es necesario asumir nuestra condición irracional y pasional, donde "pueden existir enemigos que no quieran prescindir de su enemistad, y no sólo compañeros de discusión a quienes hay que convencer; que la vida de pueblos y Estados es determinada por intereses que chocan entre sí y que no podrán dirimirse todos de manera pacífica en un tiempo previsible" (2017, p.24-25). La comprensión de esta situación resalta, entonces, nuestra vulnerabilidad como seres humanos. Evidencia las propias limitaciones y nos enfrenta al hecho de que hay contradicciones "que perviven y que quizá son irresolubles en la vida colectiva y privada” (Lehmann, 2017, p.25).

Cuestionar la supuesta estabilidad de nuestra vida personal e involucrarnos en la tragedia cotidiana de tantos otros es justamente uno de los mayores valores del arte $\mathrm{y}$, sin duda, de esta pieza teatral.

\section{Referencias bibliográficas}

Balibrea, M.P. (2007). Tiempo de exilio. Una mirada crítica a la modernidad española desde el pensamiento republicano en el exilio. Barcelona: Montesinos.

Benedetti, M. (1985). El desexilio. El desexilio y otras conjeturas. Madrid: Ediciones El País.

Burgos, J. C. (2007). Indagación sobre lo trágico. Apuntes de Teatro N¹29, Santiago: Pontificia Universidad Católica de Chile, pp. 51-.61.

Clunes, A. (febrero 2016). Entrevista sostenida con el autor. Montreal: No publicada.

De la Maza, L. (2007). Apuntes sobre la tragedia contemporánea. Apuntes de Teatro $\mathrm{N}^{\circ} 129$, Santiago: Pontificia Universidad Católica de Chile, pp. 62-67.

Del Pozo, J. (2009). Les chiliens au Quebec. Immigrants et réfugiés, de 1955 a nous jours. Montreal: Boréal.

Diderot, D. (2009). De la poesía dramática. Madrid: ADE.

Dubatti, J. (2002). El teatro jeroglífico. Herramientas de poética teatral. Buenos Aires: Atuel.

Faber, S. (2004) "Max Aub, Conciencia del Exilio" Max Aub, conciencia del exilio." Diablo texto: revista de crítica literaria. [en línea]. 7: 25-52. Consultado el 25 de agosto de 2019. https://drive.google.com/file/d/0B9LJP3L7S-IEeklWdjRweEtpVlE/view

Fisher Lichte, E. (2011). Estética de lo performativo. Madrid: Abada Editores. 
Verónica Sentis Herrmann

Gallina, A. (2016). Dramaturgia y Exilio. Poéticas radicales. Bilbao: Artezblai.

Guillén, C. (1998). Del destierro al destiempo. Múltiples Moradas, Barcelona: Tusquets, pp. 8186.

Jensen, S. (2009). Representaciones del exilio y de los exiliados en la historia argentina [en línea] E.I.A.L., Vol. 20- $\mathrm{N}^{\circ} 1$. Consultado el 18 de julio de 2019. 19-40

URL: http://eial.tau.ac.il/index.php/eial/article/viewFile/313/284

Lehmann, H. T. (2017). Tragedia y teatro dramático. México: Paso de Gato.

Lescot, D. (2013). Realismo. Léxico del drama moderno y contemporáneo, Jean Pierre Sarrazac (Dir.). México: Paso de gato, pp. 195-197.

Lesky, A. (1966). La tragedia griega. Barcelona: Editorial Labor.

Lorenzano, S. (2002). Testimonios de la memoria. Sobre exilio y literatura argentina. México, país de refugio. La experiencia de los exilios en el siglo XX. Coord. Pablo Yankelevich. México: Conaculta, pp. 321-338.

Moss, J. (2004). Immigrant theatter: Traumatic departures and unsettlin arrivals. Textualizing the immigrant experience in contemporary Quebec. Edited by Susan Ireland \&Patrice J. Proulx. Westport, Connecticut/ London: Praeger, pp. 65-81.

Retamal, M. (1997). L'Attente. Théâtre. La Espera. Teatro. Rimousky (Quebec): Éditeq. . (febrero de 2016). Entrevista sostenida con el autor. Montreal: No publicada.

Said, E. (2005). Reflexiones sobre el exilio. Ensayos literarios y culturales. España: Debate.

Shklar, J. (1998) Obligation, Loyalty, Exile. Political Thought \& Political Thinkers. Chicago and London: U Chicago, pp. 38-55.

Trigo, A. (2003). Memorias migrantes. Testimonios y ensayos sobre la diáspora uruguaya.

Rosario: Beatriz Viterbo.

Vasquez-Bronfman, A. (1991) La malédiction d'Ulysse. Hermes [En línea]. 10: 213-24.

Consultado el 5 de septiembre de 2019.

http://documents.irevues.inist.fr/bitstream/handle/2042/15396/HERMES_1992_10_213. pdf? sequence $=1$

Villegas, J. (1997) Para un modelo de historia del teatro. Estados Unidos: Gestos.

Williams, R. (2014). Tragedia moderna. Buenos Aires: Edhas. 